\title{
Number of type 2 diabetes patients achieving HbA1c goal and Related Factors in Brazil: A real world evidence study
}

Lillian Harder ( $\square$ lillian.harder@merck.com )

MSD

Tarik K Andrade

MSD Brazil

Fernando B Serra

MSD Brazil

Felipe M Pinho

TechTrials

Adolfo Pinzon

MSD Chile

Juan Carlos Orengo

Merck \& Co Inc

\section{Research}

Keywords: Type 2 diabetes, therapeutic target achievement, glycated hemoglobin, comorbidities, correlation analysis, and clinical inertia

Posted Date: August 19th, 2020

DOl: https://doi.org/10.21203/rs.3.rs-61621/v1

License: (c) (1) This work is licensed under a Creative Commons Attribution 4.0 International License.

Read Full License 


\section{Abstract \\ Background}

Despite the clinical advances in the management of type 2 diabetes mellitus (T2DM) over the past decades, in the US, nearly $48 \%$ of patients do not achieve the ADA recommended glycemic goal of glycated hemoglobin ( $\mathrm{HbA1c}$ ) below 7.0\%1 ${ }^{1}$. The Brazilian Guidelines for the Treatment of T2DM has established the same goal of $\mathrm{HbA} 1 \mathrm{c}$ below $7.0 \%{ }^{2}$, but the data for the rate of glycemic goal achievement in Brazil is lacking. The aim of this study was to determine the rate of $\mathrm{HbA} 1 \mathrm{c}$ goal achievement among Brazilian patients receiving antidiabetic therapy and investigate its relation to other clinical and demographic covariates.

\section{Methods}

Using a cross-sectional database analysis from a group of private clinics in São Paulo, Brazil, this Real Word Evidence study evaluated 1034 patients with T2DM, which were being treated with at least one antidiabetic agent for a minimum of three months and had a basal level of Glycated Hemoglobin (HbA1c) above $7.0 \%$. The number of patients that did not achieve the therapeutic target of $\mathrm{HbA1c}$ below $7 \%$ was calculated. Demographic and clinical characteristics were collected and a correlation analysis with the treatment target achievement was performed.

\section{Results}

The average age of the population was 60.5 years and gender were equally distributed. A total of $60.3 \%$ of the patients did not achieve the target of $\mathrm{HbA} 1 \mathrm{c}$ below $7 \%$ after a minimum of three months treatment with one or more antidiabetic agents. The average time between $\mathrm{HbA} 1 \mathrm{c}$ basal to final was 9.9 months. The average basal level of $\mathrm{HbA} 1 \mathrm{c}$ was $9.9 \% \pm 2.2$ and the final level was $7.8 \% \pm 1.9$. In the univariate analysis a statistically significant difference was observed in the following clinical variables: age, total cholesterol level, LDL level, basal and final $\mathrm{HbA} 1 \mathrm{c}$, time to $\mathrm{HbA} 1 \mathrm{c}$ final measure, treatment time, and number of antidiabetic agents.

\section{Conclusion}

In this retrospective real-world study, only $40 \%$ of patients achieved the glycemic target of $\mathrm{HbA} 1 \mathrm{c}$ below $7 \%$ after at least 3 months of treatment with one or more antidiabetic agent. The average initial HbA1c was $9.9 \%$ and the final level was $7.8 \%$. Patients not at goal were older and had more comorbidities, which highlight the challenge that represents the management of diabetes in Brazil. This study confirms previous published data that T2DM glycemic targets are difficult to achieve and the reasons for this are complex and multifactorial 


\section{Background}

According to the latest estimates of the International Diabetes Federation (IDF), in 2019, Brazil had 16.8 million people between 20 and 79 years with type 2 diabetes mellitus (T2DM), ranking the country as the fifth nation in number of patients with diabetes worldwide ${ }^{3}$. It is estimated that the number of people with diabetes in Brazil will increase to 23.5 million in 2040. The overall prevalence of diabetes in Brazil is $8.5 \%$ for this age group, but this prevalence can reach approximately $20 \%$ in older patients with more than 65 years $^{3}$. Another important problem to consider is the fact that 40 to $50 \%$ of these patients have not been diagnosed, and therefore are not being treated ${ }^{3}$.

The main goal of diabetes treatment is to achieve and maintain sustained glycemic control, along with managing the microvascular and macrovascular complications associated with the disease; these complications which result from long term hyperglycemia represent the main cause of morbidity and mortality in patients with T2DM 4 . To achieve and maintain optimal glycemic control, prompt treatment intensification is recommended for patients who do not achieve their glycemic goals and consistent monitoring is necessary to evaluate changes in glycemic control over time. Despite the clinical advances in the management of type 2 diabetes over the past few decades, nearly $48 \%$ of the patients with type 2 diabetes do not achieve the ADA recommended glycemic goal of glycated hemoglobin $(\mathrm{HbA} 1 \mathrm{c})<7.0 \%$ in the US ${ }^{4}$. The Brazilian Guidelines for the Treatment of Type 2 Diabetes has established the same goal for $\mathrm{HbA} 1 \mathrm{c}<7 \%^{2}$, but there is a lack of local data for the rate of glycemic goal achievement in Brazil. Clinical Inertia has been reported to be one of the reasons for inadequate blood glucose control in patients with type 2 diabetes, and it has been reported that clinical inertia occurs in $>50 \%$ of patients with type T2DM in the US ${ }^{4}$.

This study aimed to determine the rate of HbA1c goal achievement among Brazilian patients receiving antidiabetic therapy and investigate its relation to clinical and demographic covariates.

\section{Methods}

\section{Study Design and Population}

This was a retrospective, population-based, cross-sectional non interventional study that utilized data collected from the "Dr. Consulta” group of private clinics in São Paulo, Brazil, from December $1^{\text {st }}, 2013$ to October $1^{\text {st }}, 2018$. Patients diagnosed with T2DM aged $\geq 18$ years undergoing antidiabetic therapy for at least 90 days were considered for analysis. Patients with initial $\mathrm{HbA} 1 \mathrm{c}<7.0 \%$, and patients with second $\mathrm{HbA} 1 \mathrm{c}$ assessment $<90$ days were excluded from the analysis. For patients with consecutive HbA1c assessments, only the latest measurement was considered. Other clinical and demographic characteristics such as age, BMI, systolic and diastolic blood pressure, serum cholesterol, serum LDL, serum creatinine and comorbidities were also collected.

\section{Study Objectives}


The primary objective of this study was to describe the number of patients with type 2 diabetes mellitus on antidiabetic therapy for at least 3 months who were not at the HbA1c goal of less than $7.0 \%$

The secondary objectives were to analyze these populations and describe their association according to (1) Demographic and clinical characteristics; (2) presence of comorbidities; and (3) number antidiabetic agents used.

\section{Statistical Analysis}

For the primary objective, the prevalence of patients on antidiabetic therapy for a minimum of 3 months who did not achieve $\mathrm{HbA} 1 \mathrm{c}$ goal of $<7.0 \%$ were described as simple proportion.

Descriptive analyses were performed for all relevant demographic and clinical characteristics. For inferential analysis, comparison through parametric tests (Student $t$, ANOVA, ANCOVA) for normal distribution samples, or through non-parametric tests (Wilcoxon-Mann-Whitney, Kruskall-Wallis) for nonnormal distribution samples were performed.

Categorical variables were characterized by frequency and proportion (\%). Comparisons were made using chi-square or Fisher's exact tests.

\section{Results}

\section{Patient demographics and clinical characteristics}

A total of 1946 patients diagnosed with T2DM were identified in the database. Following study criteria, 582 of these patients had a basal HbA1c measurement $<7.0 \%$ and were not included in the analysis; 330 patients also did not have a second $\mathrm{HbA} 1 \mathrm{c}$ measurement $\geq 90$ days after the first, probably due to clinical inertia, and were also not included in the analysis, consequently, a total of 1034 patients were analyzed for the primary and secondary objectives, as shown in Figure 1. Details on the demographic and clinical characteristics of the study patients are presented in Table 1. A total of $49.9 \%$ of the patients were male; mean age of study participants was 60.5 years old. Mean body mass index (BMI) was $29.1 \mathrm{~kg} / \mathrm{m}^{2}$; mean systolic and diastolic blood pressure were 136.1 and $78.9 \mathrm{mmHg}$, respectively; mean serum cholesterol was $180.7 \mathrm{mg} / \mathrm{dl}$; mean LDL-C was $105.4 \mathrm{mg} / \mathrm{dl}$; and mean serum creatinine was $0.9 \mathrm{mg} / \mathrm{dl}$.

Figure 1. Patients included in the analysis according to study criteria

Table 1. Baseline demographic and clinical characteristics of the study population 


\begin{tabular}{|ll|}
\hline Characteristic & Mean (SD) \\
\hline Gender, $\mathrm{n}(\%)$ & \\
\hline Male & $516(49.9 \%)$ \\
\hline Female & $518(50.1 \%)$ \\
\hline Age (years) & $60.5(12.0)$ \\
\hline BMl $\left(\mathrm{Kg} / \mathrm{m}^{2}\right)$ & $29.1(5.6)$ \\
\hline Systolic blood pressure $(\mathrm{mmHg})$ & $136.1(20.5)$ \\
\hline Diastolic blood pressure $(\mathrm{mmHg})$ & $78.9(10.9)$ \\
\hline Cholesterol (mg/dl) & $180.7(45.6)$ \\
\hline LDL-C $(\mathrm{mg} / \mathrm{dl})$ & $105.4(36.6)$ \\
\hline Creatinine $(\mathrm{mg} / \mathrm{dl})$ & $0.9(0.3)$ \\
\hline
\end{tabular}

\section{Number of patients achieving HbA1c Goal}

In the study population, the average basal $\mathrm{HbA} 1 \mathrm{c}$ was $9.9 \% \pm 2.2$, and the average final $\mathrm{HbA} 1 \mathrm{c}$ was $7.8 \% \pm$ 1.9. Patients had a minimum of two HbA1c assessments, spaced by at least 90 days; mean interval between baseline and final $\mathrm{HbA} 1 \mathrm{c}$ measurement was $14.1 \pm 10.0$ months.

In total, 624 patients did not achieve glycemic target ( $\mathrm{HbA} 1 \mathrm{c}<7 \%)$, while the remaining 410 patients did achieve the treatment target, as shown in Figure 2.

Figure 2. Proportion of patients with $\mathrm{HbA} 1 \mathrm{c}<7 \%$ after minimum 3 months treatment

\section{Prevalence of comorbidities}

The prevalence of nutritional status and comorbidities were evaluated for the total population. For nutritional status, patients were classified based on the WHO criteria. Significant comorbidities such as hypertension, elevated cholesterol, elevated LDL, chronic kidney disease and retinopathy were classified separately, while all other comorbidities (Atrial fibrillation, angina pectoris, myocardial infarction, congestive heart failure, stroke, transient ischemic attack, chronic liver disease, renal replacement therapy, dementia, depression, amputation, peripheral neuropathy, retinopathy, peripheral vascular disease, rheumatoid arthritis, NAFLD) were grouped as OTHER, due to the very low prevalence of each one individually registered in the database. Patients who presented one or more comorbidities were considered as positive for comorbidities.

A total of $941 / 1034(91.0 \%)$ of patients presented with at least one comorbidity. The number of comorbidities varied from zero to seven. The prevalence of all registered comorbidities in this patient 
population are described in Table 2.

Table 2. Prevalence of comorbidities in the study population

\begin{tabular}{|lll|}
\hline & Frequency & Percentage \\
\hline At least one comorbidity & $941 / 1034$ & $91.0 \%$ \\
\hline Nutritional status & & \\
\hline Normal* (BMI <25.0) & $236 / 1034$ & $22.8 \%$ \\
\hline Pre-obesity (BMI 25.0 - 29.9) & $395 / 1034$ & $38.2 \%$ \\
\hline Obesity I (BMI 30.0 - 34.9) & $265 / 1034$ & $25.6 \%$ \\
\hline Obesity II (BMI 35.0 - 39.9) & $95 / 1034$ & $9.2 \%$ \\
\hline Obesity III (BMI >40.0) & $43 / 1034$ & $4.2 \%$ \\
\hline Hypertension & $359 / 1034$ & $34.7 \%$ \\
\hline Elevated cholesterol & $285 / 993$ & $28.7 \%$ \\
\hline Elevated LDL & $211 / 994$ & $21.2 \%$ \\
\hline Chronic kidney disease (CKD) & $31 / 1034$ & $3.0 \%$ \\
\hline Retinopathy & $54 / 1034$ & $5.2 \%$ \\
\hline Other comorbidities & $192 / 1034$ & $18.6 \%$ \\
\hline
\end{tabular}

*9 patients would be considered as underweight. For the purposes of this analysis, those patients were categorized as normal nutritional status.

\section{Antidiabetic therapy and number of agents prescribed.}

The mean antidiabetic treatment time was $11.1 \pm 6.4$ months for the study population. The number of antidiabetic agents prescribed varied from 1 to 5 , including oral medications and insulin.

Patients were classified as: Oral Monotherapy (without insulin); Oral Dual therapy (without insulin); Oral Triple or more (without insulin); Insulin (as monotherapy) or Insulin in combination with one or more oral agents. The proportion of patients in each category is shown on Figure 3.

Figure 3. Proportion of patients according to prescribed antidiabetic therapy

Comparison of clinical and demographic variables between patients, classified according to diabetes control ( $\mathrm{HbA} 1 \mathrm{c}<$ or $\geq 7 \%)$ - univariate analysis

Clinical and demographic variables, as well as comorbidities and number of antidiabetic agents were compared between the groups of patients that achieved and didn't achieve the HbA1c goal of $<7.0 \%$, as 
shown in Table 3, Table 4 and Table 5.

Table 3. Comparison of clinical and demographical characteristics between $\mathrm{HbA1c}$ goal achievement groups

\begin{tabular}{|llll|}
\hline & $\begin{array}{l}\text { Final HbA1c } \\
\geq 7 \% \\
\text { (Diabetes not } \\
\text { controlled) }\end{array}$ & $\begin{array}{l}\text { Final HbA1c }<7 \% \text { (Diabetes } \\
\text { controlled) }\end{array}$ & \\
\hline $\mathrm{N}$ & 624 & 410 & \\
\hline & Frequency (\%) & Frequency (\%) & $\mathbf{p}^{*}$ \\
\hline Female & $333(53.4 \%)$ & $185(45.1 \%)$ & $0.011^{*}$ \\
\hline Male & $291(46.6 \%)$ & $225(54.9 \%)$ & \\
\hline & Mean \pm SD & Mean \pm SD & 0.009 \\
\hline Age (years) & $61.3 \pm 11.8$ & $59.3 \pm 12.3$ & 0.448 \\
\hline BMI (Kg/m ${ }^{2}$ ) & $29.0 \pm 5.6$ & $29.2 \pm 5.6$ & 0.166 \\
\hline Systolic blood pressure (mmHg) & $136.8 \pm 20.8$ & $135.0 \pm 20.1$ & 0.930 \\
\hline Diastolic blood pressure (mmHg) & $78.9 \pm 11.2$ & $79.0 \pm 10.4$ & $<0.001$ \\
\hline Cholesterol (mg/dl) & $184.8 \pm 47.4$ & $174.4 \pm 42.0$ & 0.028 \\
\hline LDL-C (mg/dl) & $107.5 \pm 37.7$ & $102.3 \pm 34.6$ & 0.169 \\
\hline Creatinine (mg/dl) & $0.9 \pm 0.3$ & $0.9 \pm 0.4$ & 0.020 \\
\hline Basal HbA1c (\%) & $10.0 \pm 2.1$ & $9.7 \pm 2.3$ & 0.001 \\
\hline Final HbA1c (\%) & $8.9 \pm 1.8$ & $6.2 \pm 0.5$ & $<0.001$ \\
\hline Final - Baseline HbA1c measurement & $15.1 \pm 10.5$ & $12.5 \pm 8.8$ & 0.001 \\
\hline interval (months) & $11.7 \pm 6.5$ & $10.3 \pm 6.3$ & $1.8 \pm 0.7$ \\
\hline Treatment time (months) & $2.3 \pm 0.9$ & & \\
\hline Number of antidiabetic agents & & & \\
\hline
\end{tabular}

* Yates continuity corrected Chi-square test

** Student $\mathrm{t}$ test

Table 4. Comparison of the prevalence of comorbidities between HbA1c goal achievement groups 


\begin{tabular}{|llll|}
\hline & $\begin{array}{l}\text { Final HbA1c } \geq 7 \% \\
\text { (Diabetes not } \\
\text { controlled) }\end{array}$ & $\begin{array}{l}\text { Final HbA1c }<7 \% \text { (Diabetes } \\
\text { controlled) }\end{array}$ & p* \\
\hline $\begin{array}{l}\text { Frequency (\%) comorbidity (at least } \\
\text { one) }\end{array}$ & $571 / 624(91.5 \%)$ & $370 / 410(90.2 \%)$ & 0.560 \\
\hline Nutritional status & & & \\
\hline Normal & $148 / 624(23.7 \%)$ & $88 / 410(21.5 \%)$ & \\
\hline Pre-obesity & $236 / 624(37.8 \%)$ & $159 / 410(38.8 \%)$ & \\
\hline Obesity I & $155 / 624(24.8 \%)$ & $110 / 410(26.8 \%)$ & \\
\hline Obesity II & $62 / 624(9.9 \%)$ & $33 / 410(8.0 \%)$ & 0.963 \\
\hline Obesity III & $23 / 624(3.7 \%)$ & $20 / 410(4.9 \%)$ & 0.071 \\
\hline Hypertension & $217 / 624(34.8 \%)$ & $142 / 410(34.6 \%)$ & 0.331 \\
\hline Elevated cholesterol & $185 / 599(30.9 \%)$ & $100 / 394(25.4 \%)$ & 0.052 \\
\hline Elevated LDL-C & $134 / 600(22.3 \%)$ & $77 / 394(19.5 \%)$ & 0.264 \\
\hline $\begin{array}{l}\text { Chronic kidney disease } \\
\text { (CKD) }\end{array}$ & $13 / 624(2.1 \%)$ & $18 / 410(4.4 \%)$ & 0.007 \\
\hline Retinopathy & $37 / 624(5.9 \%)$ & $17 / 410(4.1 \%)$ & \\
\hline Other comorbidities & $133 / 624(21.3 \%)$ & $59 / 410(14.4 \%)$ & \\
\hline
\end{tabular}

* Chi-square test

Table 5. Comparison of antidiabetic treatment regimens between $\mathrm{HbA1c}$ goal achievement groups 


\begin{tabular}{|llll|}
\hline & $\begin{array}{l}\text { Final HbA1c } \geq 7 \% \\
\text { (Diabetes not } \\
\text { controlled) }\end{array}$ & $\begin{array}{l}\text { Final HbA1c }<7 \% \text { (Diabetes } \\
\text { controlled) }\end{array}$ & \\
\hline $\mathrm{N}$ & 624 & 410 & $\mathbf{p}^{*}$ \\
\hline Monotherapy (without insulin) & Frequency (\%) & Frequency (\%) & $<0.001$ \\
\hline Dual therapy (without insulin) & $112(17.9 \%)$ & $167(40.7 \%)$ & 0.011 \\
\hline Triple therapy (without insulin) & $200(32.1 \%)$ & $164(40.0 \%)$ & $<0.001$ \\
\hline Insulin (as monotherapy) & $131(21.0 \%)$ & $45(11.0 \%)$ & 0.426 \\
\hline $\begin{array}{l}\text { Insulin in combination with one or } \\
\text { more oral agent }\end{array}$ & $13(2.1 \%)$ & $5(1.2 \%)$ & $<0.001$ \\
\hline
\end{tabular}

* Yates continuity corrected Chi-square test: $p<0.001$

\section{Discussion:}

This was a retrospective, cross-sectional population-based real world study to determine the percentage of patients with T2DM achieving $\mathrm{HbA} 1 \mathrm{c}$ goal $<7 \%$ after treatment with one or more antidiabetic agent for at least 90 days in a network of private clinics in São Paulo, Brazil. A total of 1034 patients were included in a retrospective database analysis. A total of $624(60.3 \%)$ patients did not achieve the target $(\mathrm{HbA} 1 \mathrm{c}<$ $7 \%)$, while the remaining 410 patients (39.7\%) achieved the treatment goal. The average initial HbA1c was $9.9 \pm 2.2 \%$ and the average final $\mathrm{HbA} 1 \mathrm{c}$ was $7.8 \pm 1.9 \%$. These two results highlight the great challenge that represents the management of T2DM in Brazil. Actually, the percentage of patients that achieved glycemic control is similar to other previous published studies (approximately 40 to $50 \%$ ) ${ }^{8,9}$. It is also interesting to note that although all these patients were being treated with at least one antidiabetic agent for a period of at least 3 months, the final average $\mathrm{HbA} 1 \mathrm{c}$ for the total population evaluated was $7.8 \%$, which is above the recommended treatment target of $\mathrm{HbA} 1 \mathrm{c}<7 \%$. Probably one of the reasons for this finding could be related to clinical inertia.

Another important result observed in this study is the percentage of patients that are above the WHO recommended weight and BMI. Only $22 \%$ of the patients were considered normal and had a BMI < $25 \mathrm{~kg} / \mathrm{m}^{2}$. Considering that T2DM is a complex metabolic disease and that its adequate control depends, among other factors on adequate weight control, these results should be viewed as an alert to all professionals who deals with this increasingly prevalent and serious disease ${ }^{11,12}$.

Concerning the analysis of the number of antidiabetic agents prescribed and the relation with the achievement of diabetes control, it is interesting to mention that there is an inverse relation, which means that the higher the number of prescribed agents the lower the chance to achieve the glycemic control 
$(\mathrm{HbA} 1 \mathrm{c}<7 \%)$. This finding could be interpreted as that in order to achieve effective glycemic control in patients with T2DM involves more than just prescribing medications. Many other factors are involved in the management of these very complex patients such as understanding the prescription and adherence to treatment, the individual metabolic response to therapy or patients with multiple agents may have a more severe disease, adherence to the recommended lifestyle changes including diet restrictions, physical activity and adequate weight management. Other important factor involves the presence of other comorbidities, that are amazingly frequent in these patients ${ }^{13-15}$.

In the population studied, a total of $91 \%$ had at least one additional clinical condition. The most prevalent associated conditions were being overweight and obese (77\%), followed by hypertension (34.7\%), elevated cholesterol (28.7\%), elevated LDL $(21.2 \%)$, retinopathy $(5,2 \%)$. It's worth to mention the relative low prevalence of chronic renal disease in the population studied (3.0\%).

An additional important factor in the management of T2DM is clinical inertia or delay of treatment intensification which has been reported to be one of the main causes of inadequate glycemic control in patients with T2DM. Clinical inertia has been defined as failure by health care professionals to initiate or intensify treatment when glycemic targets have not been met. The ADA guidelines recommend addition of a second oral or injectable agent if metformin monotherapy fails to achieve or sustain the desired glycemic goals after 2 to 3 months. It has been reported that clinical inertia occurs in $>50 \%$ of patients with T2DM in the United States ${ }^{3}$.

The average treatment time (treatment initiation with antidiabetic agents until last $\mathrm{HbA} 1 \mathrm{c}$ assessment) for patients was 11.1 months, while the interval between baseline and final HbA1c assessments was 14.1 months. Although this cannot be considered as a measure of treatment inertia, it somehow shows that the decision to start the pharmacological treatment in this group of patients should be reviewed, since a correct timing for treatment intensification is an important factor for T2DM management ${ }^{29}$.

In the univariate statistical analysis, the following variables were found to be statistically different among the two groups: a) gender, b) age, c) cholesterol level, d) LDL level, e) basal HbA1c, f) final HbA1c, g) time period between $\mathrm{HbA} 1 \mathrm{c}$ basal to final $\mathrm{h}$ ) treatment time, i) Dr. Consulta`s follow up time, j) number of antidiabetic agents prescribed, and $k$ ) the number of associated comorbidities. Despite the fact that the variables of age, cholesterol, LDL levels, and the HbA1c initial and final levels demonstrated a statistical significant difference between the two groups, the clinical relevance of these findings does not seem to be very important since the data are very similar and are also within a range that could not really be considered as a major medical issue. A possible explanation for this is the large number of patients evaluated, and the statistical possibility that small numerical differences between groups may have statistical differences, without real clinical relevance. However, gender, number of antidiabetic agents prescribed, number of comorbidities and the three different evaluations of treatment periods demonstrated an inverse relation with the achievement of the treatment goal and this seems to have an important clinical significance since they might represent an estimation of the severity of the T2DM or, eventually, the real world difficulties in managing these more complex patients as discussed above.

Page $10 / 16$ 


\section{Conclusion}

In this real world study, which analyzed 1034 patients with type 2 diabetes, only $40 \%$ of patients achieved the glycemic target of $\mathrm{HbA} 1 \mathrm{c}<7 \%$ after at least 3 months of treatment with one or more antidiabetic agent; the remaining $60 \%$ did not achieve the target of $\mathrm{HbA} 1 \mathrm{c}<7 \%$. The average initial $\mathrm{HbA} 1 \mathrm{c}$ was $9.9 \%$ and the final level was $7.8 \%$. Patients not at goal were older and had more comorbidities, which highlight the challenge that represents the management of diabetes in Brazil. This study confirms previous published data that type 2 diabetes glycemic targets are difficult to achieve and the reasons for this are complex and multifactorial

Further observational and randomized studies should be conducted in order to better understand the complex and multifactorial aspects of T2DM management.

\section{Abbreviations}

T2DM: Type 2 diabetes

ADA: American Diabetes association

HbA1c: Glycated hemoglobin

CKD: Chronic kidney disease

\section{Declarations}

\section{Ethics approval and consent to participate}

Not Applicable. This analysis was performed in accordance with current Brazilian legislation (Lei 13.709 de 14 de Agosto de 2018), Informed Consent is not applicable to this data.

\section{Consent for publication}

Not applicable

\section{Availability of data and materials}

The data that support the findings of this study are available from "Dr. Consulta Centro Médico LTDA" but restrictions apply to the availability of these data, which were used under license for the current study, and so are not publicly available. Data are however available from the authors upon reasonable request and with permission of "Dr. Consulta Centro Médico LTDA".

\section{Competing Interests}


LH, TA, AP, JCO and FS. are employees of Merck Sharp \& Dohme Corp., a subsidiary of Merck \& Co., Inc., Kenilworth, NJ USA, who may own stock and/or hold stock options in Merck \& Co., Inc., Kenilworth, NJ, USA.

\section{Funding}

This study was sponsored by MSD Brazil, Manuscript processing and fees were also funded by MSD Brazil.

\section{Authors' Contributions}

FP, FS, JCO, LH and TA conceptualized and designed the study; AP, FP, LH and TA analyzed the data; AP, FP, LH and TA interpreted and reviewed the results; FP, LH, and TA drafted the text. All authors read and approved the final manuscript.

\section{References}

1. Stark Casagrande S, Fakdkin JE et al. The prevalence of meeting A1C, blood pressure and LDL goals among people with diabetes. Diabetes Care 2013; 36:2271-2279.

2. Brazilian Society of Diabetes Guidelines: Management of Type 2 Diabetes. 2019.

3. IDF Diabetes Atlas. $9^{\text {th }}$ Edition 2019.

4. Mahabeleshwar R et al. Patient and Provider Factors Affecting Clinical Inertia in Patients with Type 2 Diabetes on Metformin Monotherapy. Clinical Therapeutics. http://dx.doi.org/10.1016/j.clinthera.2017

5. Ali MK, Bullard KM, Saaddine JB, Cowie CC, Imperatore G, Gregg EW. Achievement of goals in US diabetes care, 1999-2010. N Engl J Med. 2013; 368(17):1613-24.

6. Okermah J, Peng J, Quiñones M. Addressing Clinical Inertia in Type 2 Diabetes Mellitus: A Review. Adv Ther 2018;35(11):1735-1745.

7. Berlowitz DR, Ash AS, Glickman M., et al. Developing a Quality Measure for Clinical Inertia in Diabetes Care. Health Serv Res 2005 Dec; 40(6 Pt 1): 1836-1853.

8. Oliveira JE, Milech A, Franco LJ. The prevalence of diabetes in Rio de Janeiro, Brazil. The Cooperative Group for the Study of Diabetes Prevalence in Rio de Janeiro. Diabetes Care, 19 (1996), pp. 663-666

9. Torquato MT, Montenegro Júnior RM, Viana LA, et al. Prevalence of diabetes mellitus and impaired glucose tolerance in the urban population aged 30-69 years in Ribeirão Preto (São Paulo), Brazil. Sao Paulo Med J, 121 (2003), pp. 224-230

10. Laiteerapong N, Ham SA, Nathan AG, Sargs RM, Quinn MT, Huang ES. National physician survey on glycemic goals and medical decision making for patients with type 2 diabetes. Medicine (Baltimore). 
2019 Dec;98(51):e18491.

11. Leitner DR1, Frühbeck G, Yumuk V, Schindler K, Micic D, Woodward E, Toplak H. Obesity and Type 2 Diabetes: Two Diseases with a Need for Combined Treatment Strategies - EASO Can Lead the Way. Obes Facts. 2017;10(5):pp.483-492.

12. Khazrai YM1, Defeudis G, Pozzilli P. Effect of diet on type 2 diabetes mellitus: a review. Diabetes Metab Res Rev. 2014 Mar;30 Suppl 1:24-33.

13. Marinho FS1, Moram CBM1, Rodrigues PC1, Leite NC2, Salles GF2, Cardoso CRL2. Treatment Adherence and Its Associated Factors in Patients with Type 2 Diabetes: Results from the Rio de Janeiro Type 2 Diabetes Cohort Study. J Diabetes Res. 2018 Nov 27;2018:8970196.

14. Bartels D. Adherence to oral therapy for type 2 diabetes: opportunities for enhancing glycemic control. J Am Acad Nurse Pract. 2004 Jan;16(1):8-16

15. Toroski M, Kebriaeezadeh A Esteghamati A, Karyani AK, Abbasian H, Nikfar S. Patient and physician preferences for type 2 diabetes medications: a systematic review. J Diabetes Metab Disord. 2019 Nov 11;18(2):643-656.

16. Cryer MJ, Horani T, DiPette DJ. Diabetes and Hypertension: A Comparative Review of Current Guidelines. J Clin Hypertens (Greenwich). 2016 Feb;18(2):95-100.

17. Rhee EJ. Nonalcoholic Fatty Liver Disease and Diabetes: An Epidemiological Perspective. Endocrinol Metab (Seoul). 2019 Sep;34(3):226-233.

18. Yau JW1, Rogers SL, Kawasaki R, Lamoureux EL,Meta-Analysis for Eye Disease (META-EYE) Study Group. Global prevalence and major risk factors of diabetic retinopathy. Diabetes Care. 2012 Mar;35(3):556-64.

19. Zhang XX, Kong J, Yun K. Prevalence of Diabetic Nephropathy among Patients with Type 2 Diabetes Mellitus in China: A Meta-Analysis of Observational Studies. J Diabetes Res. 2020 Feb 3;2020:2315607.

20. Khan RMM, Chua ZJY, Tan JC, Yang Y, Liao Z6,7, Zhao Y. From Pre-Diabetes to Diabetes: Diagnosis, Treatments and Translational Research. Medicina (Kaunas). 2019 Aug 29;55(9).

21. Erdmann E. Diabetes and cardiovascular risk markers. Curr Med Res Opin. 2005;21 Suppl 1:S21-8.

22. Terol-Fernández J, Faus-Felipe V, Díez-Rodríguez M, del Rio-Urenda S, Labajos-Manzanares MT, González-Correa JA. Prevalence of inappropriate prescription to polymedicated patients over 65 years old in a rural health area. Rev Calid Asist. 2016 Mar-Apr;31(2):84-98.

23. McAdam-Marx C1, Bellows BK, Unni S, Wygant G, Mukherjee J, Ye X, Brixner DI. Impact of adherence and weight loss on glycemic control in patients with type 2 diabetes: cohort analyses of integrated medical record, pharmacy claims, and patient-reported data. J Manag Care Spec Pharm. 2014 Jul;20(7):691-700.

24. McAdam-Marx C, Bellows BK, Unni S, Wygant G, Mukherjee J, Ye X, Brixner DI. Impact of adherence and weight loss on glycemic control in patients with type 2 diabetes: cohort analyses of integrated medical record, pharmacy claims, and patient-reported data. J Manag Care Spec Pharm. 2014 Jul;20(7):691-700.

Page 13/16 
25. Larkin AT, Hoffman C, Stevens A, Douglas A, Bloomgarden Z. Determinants of adherence to diabetes treatment. J Diabetes. 2015 Nov;7(6):864-71.

26. O'Connor PJ. Improving Diabetes Care by Combating Clinical Inertia. Health Serv Res. 2005 Dec; $40(6$ Pt 1): 1854-1861.

27. Zhu NA, Harris SB. Therapeutic Inertia in People With Type 2 Diabetes in Primary Care: A Challenge That Just Won't Go Away. Diabetes Spectr. 2020 Feb;33(1):44-49

28. Khunti S1, Khunti K2, Seidu S3. Therapeutic inertia in type 2 diabetes: prevalence, causes, consequences and methods to overcome inertia. Ther Adv Endocrinol Metab. 2019 May 3;10:2042018819844694.

29. Ajmera M, Raval A, Zhou S, Wei W, Bhattacharya R, Pan C, Sambamoorthi U. A Real-World Observational Study of Time to Treatment Intensification Among Elderly Patients with Inadequately Controlled Type 2 Diabetes Mellitus. J Manag Care Spec Pharm. 2015 Dec;21(12):1184-93.

30. Einarson TR, Acs A, Ludwig C, Panton UH. Economic Burden of Cardiovascular Disease in Type 2 Diabetes: A Systematic Review. Value Health. 2018 Jul;21(7):881-890.

31. Braunwald E. Diabetes, heart failure, and renal dysfunction: The vicious circles. Prog Cardiovasc Dis. 2019 Jul - Aug;62(4):298-302.

\section{Figures}

1946 T2DM patients undergoing antidiabetic treatment

1034 were analyzed according to study criteria

912 patients were excluded

582 had first $\mathrm{HbA} 1 \mathrm{c}$ measurement $<7.0 \%$ 330 didn't had second HbA1c measurement $\geq 90 \mathrm{~d}$

\section{Figure 1}

Patients included in the analysis according to study criteria 


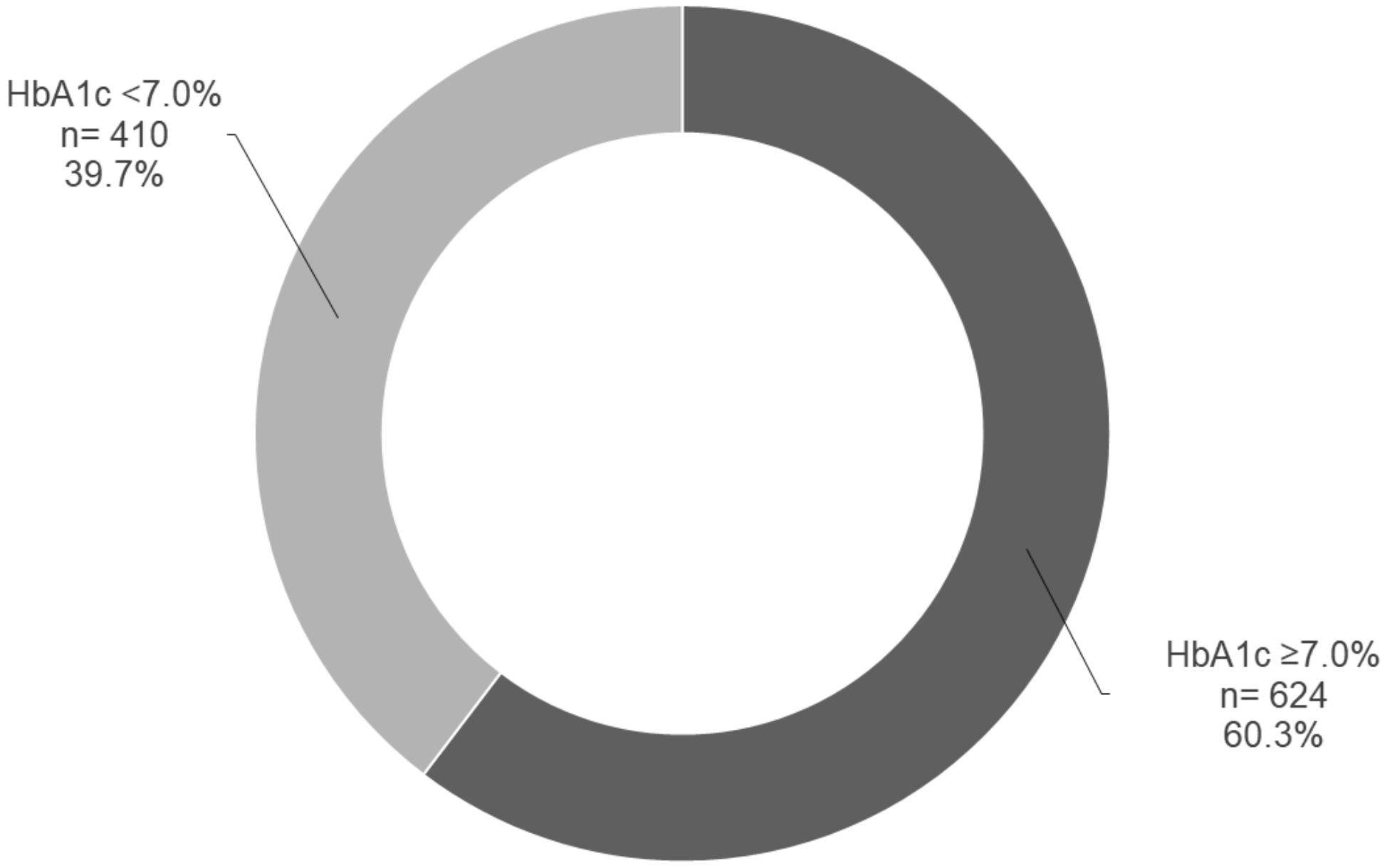

Figure 2

Proportion of patients with $\mathrm{HbA} 1 \mathrm{c}<7 \%$ after minimum 3 months treatment 


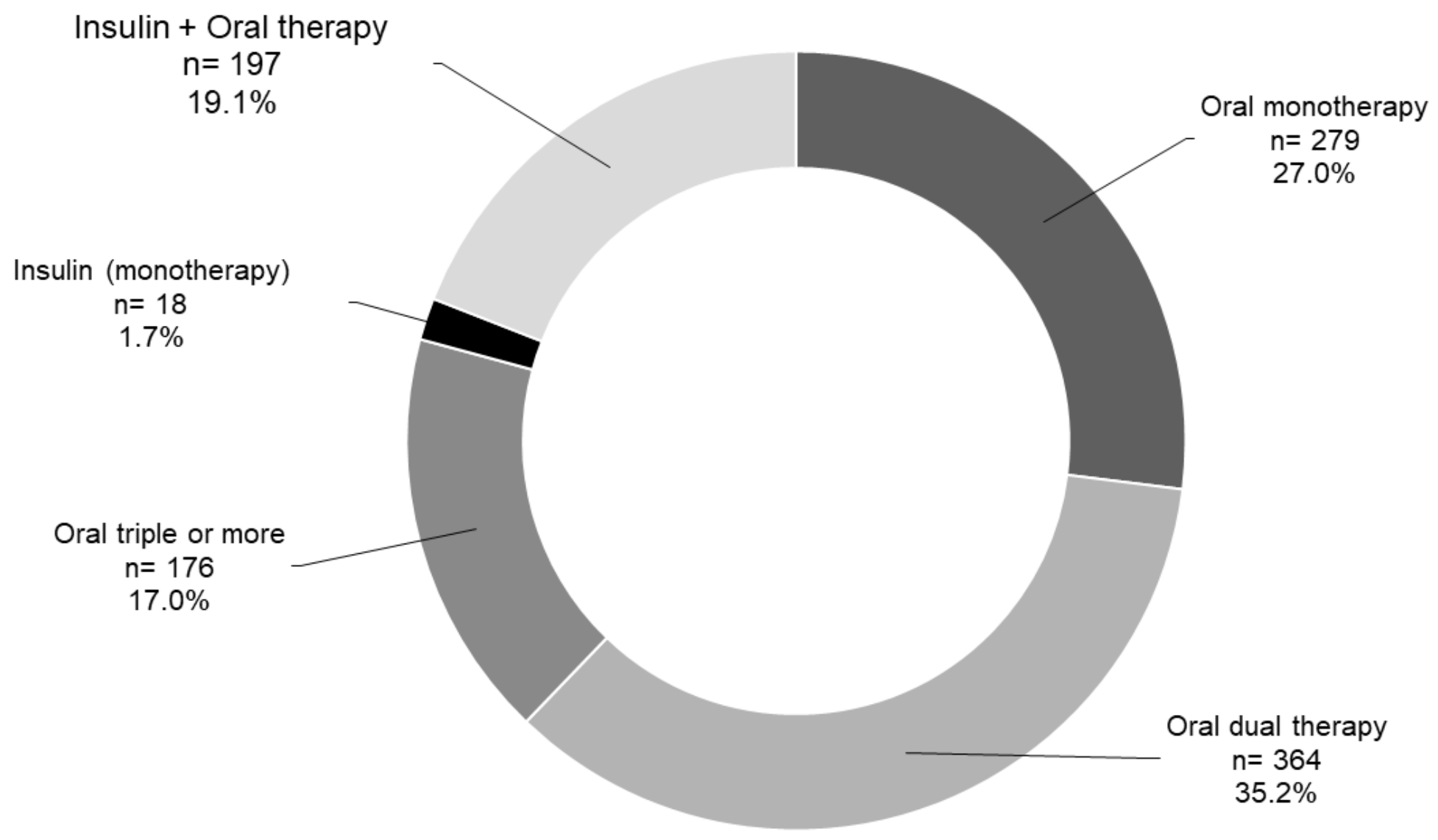

Figure 3

Proportion of patients according to prescribed antidiabetic therapy 